\title{
Pregnancy following liver transplantation: Review of outcomes and recommendations for management
}

\author{
Kuljit S Parhar MD MSc FRCPC ${ }^{1}$, Paul S Gibson MD FRCPC ${ }^{1}$, Carla S Coffin MD MSc FRCPC ${ }^{2}$
}

\begin{abstract}
KS Parhar, PS Gibson, CS Coffin. Pregnancy following liver transplantation: Review of outcomes and recommendations for management. Can J Gastroenterol 2012;26(9):621-626.
\end{abstract}

Liver transplantation is considered to be the treatment of choice for end-stage liver disease and its success has led to an increase in the number of female liver transplant recipients who are of childbearing age. Several key issues that are noted when counselling patients who are considering pregnancy following liver transplantation include the optimal timing of pregnancy, optimal contraception methods and the management of immunosuppression during pregnancy. The present review summarizes the most recent literature so that the clinician may address these issues with their patient and enable them to make informed decisions about pregnancy planning. The authors review recent studies examining maternal and fetal outcomes, and the rates of complications including risk of graft rejection. Subsequently, the authors provide recommendations for counselling prospective mothers and the management of the pregnant liver transplant recipient.

Key Words: Conception; Fetal outcomes; Immunosuppression; Liver transplantation; Maternal outcomes; Pregnancy

\begin{abstract}
The first successful liver transplants were performed in the 1960s and, in 1978, the first successful pregnancy in a liver transplant recipient was reported (1). Since then, there has been a dramatic increase in the number of successful liver transplants worldwide, with a concomitant increase in the number of women who are of childbearing age following transplantation. From 1988 until the present time, approximately 4000 women in the United States 18 to 34 years of age have received a liver transplant (2), highlighting the need for appropriate preconception counselling and management of the pregnant liver transplant recipient. The present review aims to summarize the most recent data regarding several issues including the ideal timing of conception following liver transplant, the optimal use of contraception and the use of immunosuppressant medications in pregnancy. In addition, the maternal and fetal risks associated with pregnancy will be reviewed.
\end{abstract}

\section{PRECONCEPTION PLANNING}

Physiology and timing of pregnancy

Severe chronic liver disease frequently results in disruption of the hypothalamic-pituitary-ovarian axis, leading to amenorrhea in up to $50 \%$ of women of childbearing age (3). Hormonal imbalances often occur, with both hypogonadotrophic hypogonadism and elevated levels of estrogens being reported causes $(4,5)$. Consequently, successful conception is uncommon in women with end-stage liver disease. The cause of hypogonadotrophism and amenorrhea in liver disease is multifactorial, often dependent on the etiology of the underlying liver disease and frequently related to malnutrition, which is particularly common in cirrhotic patients. Following successful liver transplantation,

\section{Une grossesse après une transplantation hépatique : l'analyse des issues et des recommandations de prise en charge}

La transplantation hépatique est considérée comme le traitement de première intention de l'insuffisance hépatique au stade terminal, et sa réussite a suscité une augmentation du nombre de femmes greffées du foie en âge de procréer. On constate plusieurs enjeux importants lorsqu'on conseille les patientes qui envisagent une grossesse après une transplantation hépatique, soit le moment optimal de la grossesse, les méthodes de contraception optimales et la prise en charge de l'immunosuppression pendant la grossesse. La présente analyse résume les documents scientifiques les plus récents sur le sujet, afin que le clinicien puisse aborder ces questions avec ses patientes et leur permettre de prendre des décisions éclairées en matière de planification de grossesse. Les auteurs ont analysé les récentes études sur les issues maternelles et fotales, et le taux de complications, y compris le risque de rejet de la transplantation. Les auteurs ont ensuite fourni des recommandations au sujet des conseils aux mères prospectives et de la prise en charge de la transplantation hépatique des greffées.

the return of regular menstruation occurs within 10 months in the majority of liver transplant recipients $(3,6)$. Approximately $30 \%$ of women may experience return of normal menstruation as soon as three months following liver transplantation; however, there is strong evidence that delaying conception for at least one year following successful liver transplantation may significantly improve maternal and fetal outcomes (7). Thus, appropriate contraception and pregnancy planning is important (6). A study from the National Transplant Registry investigating 128 pregnancies in liver transplant recipients (7) demonstrated that a transplant to conception interval $>2$ years was associated with a reduction in the rates of low birth weight newborns, rejection during pregnancy and graft loss. Although the American Society of Transplantation does not have an explicit recommendation for a suggested interval between liver transplantation and conception (8), it suggests consideration of several positive prognostic factors when counselling patients including lack of rejection episodes in the previous year, adequate and stable graft function, absence of acute infections and stable immunosuppressant dosing.

\begin{abstract}
Mode of contraception
There is limited evidence regarding the safest and most effective method of contraception following liver transplantation for prevention of an unplanned pregnancy. Although barrier methods provide the lowest theoretical risk for systemic interactions and complications, noncompliance and overall efficacy present issues. A recent systematic review on contraceptive use in solid organ transplantation (9) summarized the experiences of both kidney and liver transplant recipients who were prescribed contraception. The authors found no unplanned pregnancies and no major biochemical abnormalities during follow-up
\end{abstract}

${ }^{1}$ Division of General Internal Medicine; ${ }^{2}$ Liver Unit - Division of Gastroenterology and Hepatology, University of Calgary, Calgary, Alberta

Correspondence: Dr Carla S Coffin, Liver Unit - Division of Gastroenterology, University of Calgary, 3280 Hospital Drive Northwest, Calgary,

Alberta T2N 4Z6. Telephone 403-592-5049, fax 403-592-5090, e-mail cscoffin@ucalgary.ca

Received for publication December 12, 2011. Accepted January 2, 2012 
TABLE 1

Summary of risks related to immunosuppression during pregnancy

\begin{tabular}{ll}
\hline Drug & Reported side effects \\
\hline $\begin{array}{l}\text { Calcineurin inhibitors } \\
\text { (including cyclosporine and tacrolimus) } \\
\text { Azathioprine }\end{array}$ & Maternal diabetes, hypertension, pre-eclampsia, renal dysfunction, fetal perinatal hyperkalemia \\
& $\begin{array}{c}\text { Fetal anemia, thrombocytopenia, leucopenia, decreased fetal immunoglobulin levels, } \\
\text { neonatal infection and sepsis, preterm delivery and low birth weight }\end{array}$ \\
$\begin{array}{l}\text { Corticosteroids } \\
\text { Mycophenylate mofetil }\end{array}$ & $\begin{array}{c}\text { Gestational hypertension, gestational diabetes, fetal adrenal insufficiency, fetal cleft-palate and lip } \\
\text { Increased first trimester pregnancy loss, fetal malformation including cleft lip and palate, microtia, }\end{array}$ \\
\hline
\end{tabular}

*United States Food and Drug Administration (FDA) category definitions (Federal Register 1980;44:37434-67): Category A: Controlled studies in women fail to demonstrate a risk to the fetus in the first trimester (and there is no evidence of a risk in later trimester) and the possibility of fetal harm appears remote; Category B: Either animal-reproduction studies have not demonstrated a fetal risk but there are no controlled studies in pregnant women or animal-reproduction studies have shown an adverse effect (other than a decrease in fertility) that was not confirmed in controlled studies in women in the first trimester (and there is no evidence of a risk in later trimesters); Category C: Either studies in animals have revealed adverse effects on the fetus (teratogenic or embryocidal or other) and there are no controlled studies in women or studies in women and animals are not available. Drugs should be given only if the potential benefit justifies the potential risk to the fetus; Category D: There is positive evidence of human fetal risk, but the benefits from use in pregnant women may be acceptable despite the risk (eg, if the drug is needed in a life-threatening situation or for a serious disease for which safer drugs cannot be used or are ineffective); Category X: Studies in animals or human beings have demonstrated fetal abnormalities or there is evidence of fetal risk based on human experience or both, and the risk of the use of the drug in pregnant women clearly outweighs any possible benefit. The drug is contraindicated in women who are or may become pregnant

in patients using hormonal contraception (either oral or transdermal patch). Specifically in liver transplant recipients, a retrospective study examining 15 patients using either combined oral contraceptives (COC) or a transdermal contraceptive patch also found no clinical or biochemical abnormalities at three, six or 12 months while maintaining $100 \%$ efficacy (10). One case report of high-dose COC (50 $\mu \mathrm{g}$ ethinyl estradiol) prescribed to a liver transplant recipient for severe menorrhagia described both clinical and biochemical intrahepatic cholestasis; however, discontinuation of the COC resulted in resolution of the symptoms and normalization of the liver indexes (11). In a series of case reports on the use of intrauterine devices (IUDs) in kidney transplant recipients, $60 \%$ (three of five cases) reported treatment failures and unplanned pregnancies (reviewed in [9]). It is possible that the chronic immunosuppression following transplantation interferes with the efficacy of IUDs. Although the American Society of Transplantation recommends against offering IUDs as first-line contraceptive therapy in this population, this remains an area of debate because IUDs have been reported to be an effective approach in some patients (12). The concern that immunosuppression may predispose to an increased rate of IUD-associated pelvic infection is based on a single case report (13).

\section{RISK OF IMMUNOSUPPRESSION DURING PREGNANCY (Table 1)}

Calcineurin inhibitors - cyclosporine and tacrolimus

Calcineurin inhibitors (including cyclosporine and tacrolimus) suppress $\mathrm{T}$ cell function through inhibition of cytokines such as interleukin-2. There have been no definitive reports of cyclosporine- or tacrolimusinduced teratogenicity; rates of major fetal malformation in exposed infants have been similar to the baseline rate with no pattern of malformation noted $(14,15)$. Initial reports of calcineurin inhibitorinduced intrauterine growth restriction were not substantiated by subsequent studies $(14,16)$. In addition, the doses currently used in transplantation to achieve therapeutic levels are much lower than those used previously. Cyclosporine has been associated with increased rates of hypertension and renal dysfunction (17). Tacrolimus was associated with increased rates of pre-eclampsia, renal impairment and infection in one case series (15), as well as increased rates of diabetes during pregnancy (18). There are also reports of an increased incidence of transient neonatal hyperkalemia (14). Nevertheless, based on these data, cyclosporine and tacrolimus are classified as United States Food and Drug Administration (US FDA) category C medications and, overall, deemed as safe to use during pregnancy.

\section{Azathioprine}

Azathioprine inhibits purine metabolism, resulting in suppression of cell-mediated immunity. Azathioprine use is well studied during pregnancy, with data on several thousand pregnancies due to its widespread use not only in transplant recipients but also in many rheumatological diseases and inflammatory bowel disease. To date, there has been no definite reported link between azathioprine and teratogenicity (19).

From the fetal/neonatal perspective, there are reports of occasional hematological issues including anemia, thrombocytopenia and leucopenia. There have been case reports of decreased immunoglobulin levels, neonatal infections and sepsis, as well as chromosomal abnormalities in exposed fetuses (20). However, the overall risk appears to be quite low, particularly because the fetal liver has been shown to lack the enzyme inosinate pyrophosphorylase needed for conversion of azathioprine's metabolite 6-mercaptopurine into its active component thiouric acid (21). There have also been reports of an increased risk of preterm delivery and lower birth weight (22), although whether this relates to medication use or the underlying maternal condition is difficult to differentiate. Azathioprine is classified as a US FDA category D medication, based mainly on reports of animal studies with teratogenic effects, but this has not been corroborated with all of the human data (19). In general, most transplant physicians are quite comfortable continuing azathioprine throughout pregnancy in women who require it.

\section{Corticosteroids}

Prednisone is an important part of the antirejection regimen immediately following liver transplantation. Although initially used at high doses, within the first year, it is gradually tapered to low doses or completely discontinued. If the underlying etiology of the liver disease before transplant was autoimmune in nature or if the recipient experiences episodes of rejection, higher doses or longer courses of prednisone may be required.

The maternal risks - in addition to the typical complications of steroid use - include a predisposition to gestational hypertension and gestational diabetes mellitus (GDM) and increased rates of premature rupture of membranes have also been reported (20). In the fetus, there have been reports of increased cleft-palate and lip in animal studies (23) as well as in human exposures, with approximately a tripling of the risk of this uncommon malformation following first trimester exposure (24). In addition, there have been rare reports of fetal adrenal insufficiency $(25,26)$. The overall rate of fetal/neonatal complications is low; however, because the placenta metabolizes more than $90 \%$ of the maternal prednisone dose, fetal exposure is very limited (27). In summary, prednisone is classified as a category B medication for safe use in pregnancy based on the US FDA classification system. 
TABLE 2

Summary of published data on maternal outcomes in liver transplant recipients

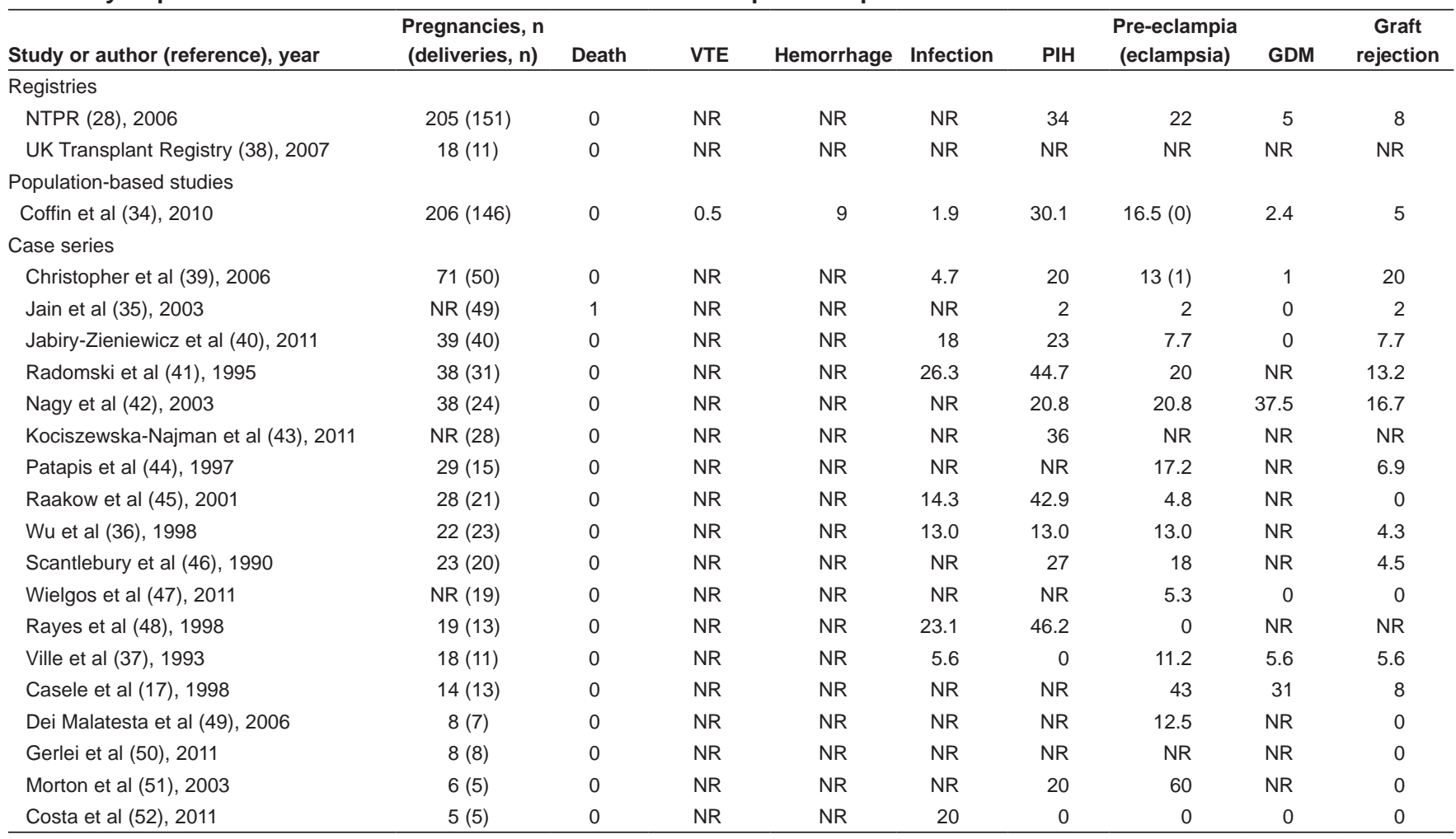

Data presented as \% unless otherwise indicated. GDM Gestational diabetes mellitus; NR Not reported; NTPR National Transplantation Pregnancy Registry; PIH Pregnancy-induced hypertension; UK United Kingdom; VTE Venothromboembolism

\section{Mycophenolate mofetil}

Mycophenolate mofetil (MMF) is a purine biosynthesis inhibitor that works by inhibiting $B$ and $T$ cell function. In the first trimester, MMF has been associated with pregnancy loss, with rates of spontaneous abortion ranging from $33 \%$ to $45 \%$ (28). There are multiple reports of malformations associated with the use of MMF during pregnancy $(29,30)$. The typical pattern of malformation involves cleft lip and palate in addition to microtia and the absence of auditory canals. There have been reports of neonatal anemia, hypoplastic nails and shortened fifth digit (31-33). As a result of this significant teratogenic risk, MMF is classified as a US FDA category D medication and should not be used during pregnancy.

\section{OUTCOMES IN PREGNANCY FOLLOWING LIVER TRANSPLANTATION}

The vast majority of data pertaining to maternal and fetal outcomes are from patient self-reported registries or from published cases series. The National Transplant Registry was established in 1991 and is a questionnaire-based registry investigating pregnancy outcomes in North American transplant recipients. The United Kingdom transplant registry, started in 1997, collects both prospective and retrospective data on pregnancies, creating a data set with patients from 1994 to 2001. In addition to these, a recent large population-based study also reported on obstetrical outcomes in liver transplant recipients (34). The majority of case series and reports are from Europe and North America, with a combined 462 pregnancies from 18 case series. Tables 2, 3 and 4 summarize the published literature to date on maternal, obstetrical and fetal outcomes.

\section{Maternal outcomes}

The major maternal outcomes are summarized in Table 2. Overall, there have been no reported associations between liver transplantation and increased rates of maternal mortality. One case series reported a single maternal fatality in a primapara at 40 years of age, who experienced an infrarenal aortic graft clot during labour and died two days later from a gangrenous allograft (35).

Pregnancy-induced hypertension has been common among liver transplant recipients, with rates varying from $2 \%$ to $43 \%$. The three largest studies report rates of between 20\% and 34\% (Table 2). Preeclampsia is also commonly seen, with rates between $2 \%$ and $22 \%$. The reported rates of GDM have varied widely, from $0 \%$ to $37.5 \%$, but in a large population-based study, the rate of GDM (2.4\%) did not vary significantly from controls.

Graft rejection rates during pregnancy varied from $0 \%$ to $20 \%$. Factors associated with graft loss within five years were reported in the recent National Transplantation Pregnancy Registry in 2009. Important predictors included Caucasian race, viral hepatitis as etiology of liver failure, age $<18$ years at time of transplant and rejection during pregnancy (7).

Obstetrical outcomes

The major obstetrical outcomes described to date are summarized in Table 3. The rates of Cesarean delivery among liver transplant recipients were consistently higher than the general nontransplant population in the majority of reports (20\% to $100 \%)$. There are several reasons postulated for this including increased rates of fetal distress as well as maternal factors such as gestational hypertension and preeclampsia. Not surprisingly, uncomplicated vaginal delivery rates (without assistance) ranged widely (0\% to $50 \%$ ).

A significant proportion of pregnancies in this population are complicated by preterm labour and delivery ( $<37$ weeks), with rates of $12.5 \%$ to $50 \%$ being reported (Table 3 ).

\section{Fetal outcomes}

Fetal outcomes are summarized in Table 4. Fetal deaths are more common in liver transplant recipients, with increased rates of spontaneous 
TABLE 3

Summary of published data on obstetrical outcomes in liver transplant recipients

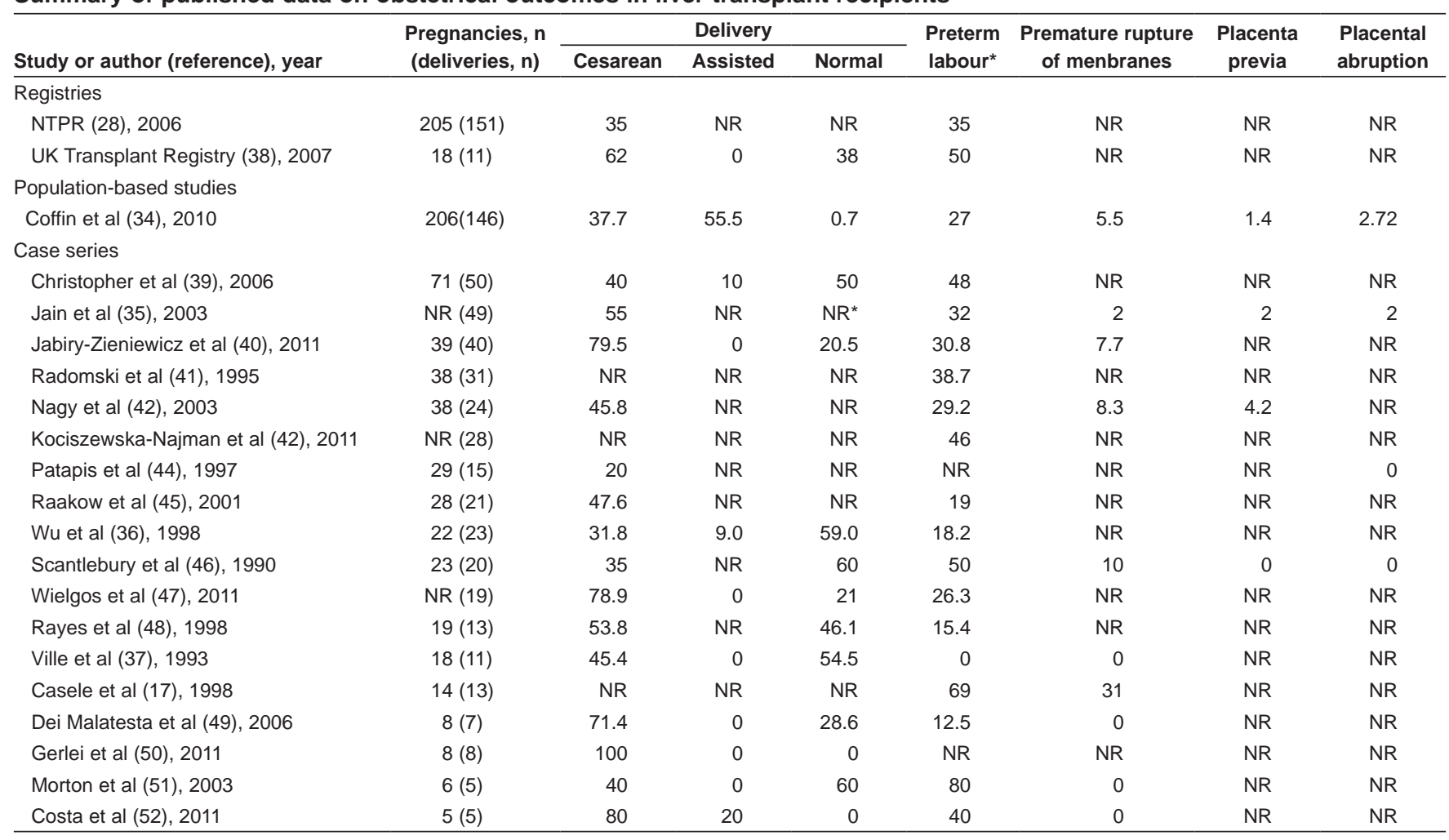

Data presented as \% unless otherwise indicated. *<37 weeks. NR Not reported; NTPR National Transplantation Pregnancy Registry; UK United Kingdom

TABLE 4

Summary of published data on fetal complications in liver transplant recipients

\begin{tabular}{|c|c|c|c|c|c|c|c|c|}
\hline Study or author (reference), year & $\begin{array}{l}\text { Pregnancies, n } \\
\text { (deliveries, n) }\end{array}$ & $\begin{array}{l}\text { Live } \\
\text { births }\end{array}$ & $\begin{array}{c}\text { Still births } / \\
\text { intrauterine } \\
\text { death }\end{array}$ & $\begin{array}{l}\text { Spontaneous } \\
\text { or missed } \\
\text { abortions }\end{array}$ & $\begin{array}{l}\text { Therapeutic } \\
\text { abortions }\end{array}$ & $\begin{array}{c}\text { IUGR } \\
(<2500 \mathrm{~g})\end{array}$ & $\begin{array}{c}\text { Fetal } \\
\text { distress }\end{array}$ & $\begin{array}{c}\text { Congenital } \\
\text { anomaly }\end{array}$ \\
\hline \multicolumn{9}{|l|}{ Registries } \\
\hline UK Transplant Registry (38), 2007 & $18(11)$ & 69 & 0 & 13 & 13 & 57 & NR & NR \\
\hline \multicolumn{9}{|l|}{ Population-based studies } \\
\hline Coffin et al (34), 2010 & $206(146)$ & 93.7 & NR & 4.9 & NR & 4.8 & 10.3 & 1.4 \\
\hline Christopher et al (39), 2006 & $71(50)$ & 71.4 & 1.4 & 18.6 & 8.6 & 30 & NR & NR \\
\hline Jain et al (35), 2003 & NR (49) & 100 & NR & NR & NR & 42.9 & NR & \\
\hline Jabiry-Zieniewicz et al (40), 2011 & $39(40)$ & 100 & NR & NR & NR & 20 & 15.4 & 0 \\
\hline Radomski et al (41), 1995 & $38(31)$ & 81.6 & NR & 15.8 & 5.3 & 32.3 & NR & NR \\
\hline Nagy et al (42), 2003 & $38(24)$ & 63.1 & 0 & 10.5 & 26.3 & 25 & 16.7 & 16.7 \\
\hline Kociszewska-Najman et al (43), 2011 & NR (28) & 100 & 0 & NR & NR & 32.1 & NR & NR \\
\hline Wielgos et al (47), 2011 & NR (19) & 19 & NR & NR & NR & 11 & NR & 0 \\
\hline Rayes et al (48), 1998 & $19(13)$ & 100 & 0 & 21.1 & 10.5 & 30.7 & 30.7 & NR \\
\hline Ville et al (37), 1993 & $18(11)$ & 100 & 0 & 22.4 & 16.67 & 9.09 & NR & 0 \\
\hline Casele et al (17), 1998 & $14(13)$ & 77 & 23 & 0 & 7.1 & $N R$ & NR & 0 \\
\hline Dei Malatesta et al (49), 2006 & $8(7)$ & 100 & NR & 12.5 & 0 & 0 & NR & 0 \\
\hline Gerlei et al (50), 2011 & $8(8)$ & 100 & NR & NR & NR & NR & $N R$ & 0 \\
\hline Morton et al (51), 2003 & $6(5)$ & 100 & 0 & 16.7 & 0 & 40 & NR & 0 \\
\hline Costa et al (52), 2011 & $5(5)$ & 100 & NR & NR & 0 & 80 & 40 & 0 \\
\hline
\end{tabular}

Data presented as \% unless otherwise indicated. IUGR Intrauterine growth restriction; NR Not reported; NTPR National Transplantation Pregnancy Registry; UK United Kingdom 
or missed abortions (4.9\% to $19 \%$ ). Stillbirths were quite uncommon, with rates of $0 \%$ to $2 \%$ being reported. Low birth weight $(<2500 \mathrm{~g})$ is also a common complication, with rates ranging from $4.8 \%$ to $57 \%$. Rates of fetal distress are also increased (10.3\% to $40 \%)$ during these pregnancies. Overall, congenital abnormalities are uncommon and minimally increased, with rates of $0 \%$ to $16.7 \%$.

Data on long-term pediatric outcomes are lacking. In a case series by Wu et al (36), six children were followed for 48 months postpartum. All children had appropriate physical development, no abnormal infectious complications and no difference in psychological development based on questionnaire data. In another case series by Ville et al (37), 11 children were followed-up for varying periods from three months to five years of age. There were no reports of abnormal physical development, adrenal or respiratory insufficiency, or lymphopenia. Overall, long-term developmental data based on neurocognitive testing are limited.

\section{SUMMARY OF RECOMMENDATIONS}

Compared with the general population, pregnancy in liver transplant recipients is associated with a greater risk of adverse maternal and fetal outcomes. However, increasing data and experience with the management of these patients has enabled minimization of these risks such that successful pregnancy is becoming an expectation for both the patient and their care providers. Based on our literature review, we provide the following general recommendations for both prepregnancy counselling and management of the pregnant liver transplant recipient:

1. Return of menstrual function is common in the months after transplantation and, thus, preconception counselling is an essential part of pregnancy planning in the liver transplant recipient of childbearing age.

2. Timing of conception is an important consideration; it is advisable to wait at least one, preferably two years following successful transplantation before conceiving. Appropriate contraceptive advice regarding use of barrier or hormonal contraception should be provided in the interim.

3. Immunosuppression should be reviewed, and the risks and benefits of each medication discussed with the patient. MMF should not be used during pregnancy given its high risks of adverse fetal effects. Calcineurin inhibitors, steroids and azathioprine are considered to be safe and appropriate choices. Due to the theoretical risk of altered drug metabolism and general immunosuppressive state of pregnancy, graft function and immunosuppression should be closely monitored.

4. Once pregnant, routine monitoring of these women for pregnancy-induced hypertension and GDM should be undertaken given the increased risk of these conditions.

5. A skilled obstetrical care provider should be consulted to monitor the fetus for congenital malformations and growth restriction, although overall the risk is considered to be low.

6. Mode of delivery should be according to the usual obstetrical indications. Although vaginal delivery is a very reasonable option in most cases, a large proportion of these women deliver via Cesarean section.

7. Multidisciplinary management and care within a tertiary care referral centre, especially during complicated pregnancies, is essential. Open and frequent communication between the obstetrical care providers and the liver transplantation team is necessary for ongoing counselling, advice regarding pregnancy planning, and graft monitoring and management during pregnancy.

\section{REFERENCES}

1. Walcott WO, Derick DE, Jolley JJ, Snyder DL. Successful pregnancy in a liver transplant patient. Am J Obstet Gynecol 1978;132:340-1.
2. U.S. Organ Procurement and Transplantation Network and the Scientific Registry of Transplant Recipients. $<$ http://optn.transplant.hrsa.gov/> (Accessed October 18, 2011).

3 Cundy TF, O'Grady JG, Williams R. Recovery of menstruation and pregnancy after liver transplantation. Gut 1990;31:337-8.

4. Bell H, Raknerud N, Falch JA, Haug E. Inappropriately low levels of gonadotrophins in amenorrhoeic women with alcoholic and non-alcoholic cirrhosis. Eur J Endocrinol 1995;132:444-9.

5. Cundy TF, Butler J, Pope RM, Saggar-Malik AK, Wheeler MJ, Williams R. Amenorrhoea in women with non-alcoholic chronic liver disease. Gut 1991;32:202-6.

6. Jabiry-Zieniewicz Z, Kaminski P, Bobrowska K, et al. Menstrual function in female liver transplant recipients of reproductive age. Transplant Proc 2009;41:1735-9.

7. Coscia LA, Constantinescu S, Moritz MJ, et al. Report from the National Transplantation Pregnancy Registry (NTPR): Outcomes of pregnancy after transplantation. Clin Transpl 2009:103-22.

8. McKay DB, Josephson MA, Armenti VT, et al. Reproduction and transplantation: Report on the AST Consensus Conference on Reproductive Issues and Transplantation. Am J Transplant 2005;5:1592-9.

9. Paulen ME, Folger SG, Curtis KM, Jamieson DJ. Contraceptive use among solid organ transplant patients: A systematic review. Contraception 2010;82:102-12.

10. Jabiry-Zieniewicz Z, Bobrowska K, Kaminski P, Wielgos M, Zieniewicz K, Krawczyk M. Low-dose hormonal contraception after liver transplantation. Transplant Proc 2007;39:1530-2.

11. Fedorkow DM, Corenblum B, Shaffer EA. Cholestasis induced by oestrogen after liver transplantation. BMJ 1989;299:1080-1.

12. Estes CM. Response to Surti et al. 'Pregnancy and liver transplantation'. Liver Int 2009;29:475; author reply, 6.

13. Zerner J, Doil KL, Drewry J, Leeber DA. Intrauterine contraceptive device failures in renal transplant patients. J Reprod Med 1981;26:99-102.

14. Jain A, Venkataramanan R, Fung JJ, et al. Pregnancy after liver transplantation under tacrolimus. Transplantation 1997;64:559-65.

15. Kainz A, Harabacz I, Cowlrick IS, Gadgil SD, Hagiwara D. Review of the course and outcome of 100 pregnancies in 84 women treated with tacrolimus. Transplantation 2000;70:1718-21.

16. Pickrell MD, Sawers R, Michael J. Pregnancy after renal transplantation: Severe intrauterine growth retardation during treatment with cyclosporin A. Br Med J (Clin Res Ed) 1988;296:825.

17. Casele HL, Laifer SA. Association of pregnancy complications and choice of immunosuppressant in liver transplant patients. Transplantation 1998;65:581-3.

18. Armenti VT, Constantinescu S, Moritz MJ, Davison JM. Pregnancy after transplantation. Transplant Rev (Orlando) 2008;22:223-40.

19. Armenti VT, Moritz MJ, Davison JM. Pregnancy in female pediatric solid organ transplant recipients. Pediatr Clin North Am 2003;50:1543-60.

20. Janssen NM, Genta MS. The effects of immunosuppressive and anti-inflammatory medications on fertility, pregnancy, and lactation. Arch Intern Med 2000;160:610-9.

21. Saarikoski S, Seppala M. Immunosuppression during pregnancy: Transmission of azathioprine and its metabolites from the mother to the fetus. Am J Obstet Gynecol 1973;115:1100-6.

22. Goldstein LH, Dolinsky G, Greenberg R, et al. Pregnancy outcome of women exposed to azathioprine during pregnancy. Birth Defects Res A Clin Mol Teratol 2007;79:696-701.

23. Fraser FC, Fainstat TD. Production of congenital defects in the off-spring of pregnant mice treated with cortisone; progress report. Pediatrics 1951;8:527-33.

24. Park-Wyllie L, Mazzotta P, Pastuszak A, et al. Birth defects after maternal exposure to corticosteroids: Prospective cohort study and meta-analysis of epidemiological studies. Teratology 2000;62:385-92.

25. Anderson GG, Rotchell Y, Kaiser DG. Placental transfer of methylprednisolone following maternal intravenous administration. Am J Obstet Gynecol 1981;140:699-701.

26. McKay DB, Josephson MA. Pregnancy in recipients of solid organseffects on mother and child. N Engl J Med 2006;354:1281-93.

27. Blanford AT, Murphy BE. In vitro metabolism of prednisolone, dexamethasone, betamethasone, and cortisol by the human placenta. Am J Obstet Gynecol 1977;127:264-7.

28. Armenti VT, Radomski JS, Moritz MJ, et al. Report from the National Transplantation Pregnancy Registry (NTPR): Outcomes of pregnancy after transplantation. Clin Transpl 2005:69-83. 
29. Sifontis NM, Coscia LA, Constantinescu S, Lavelanet AF, Moritz MJ, Armenti VT. Pregnancy outcomes in solid organ transplant recipients with exposure to mycophenolate mofetil or sirolimus. Transplantation 2006;82:1698-702.

30. Pergola PE, Kancharla A, Riley DJ. Kidney transplantation during the first trimester of pregnancy: Immunosuppression with mycophenolate mofetil, tacrolimus, and prednisone. Transplantation 2001;71:994-7.

31. Anderka MT, Lin AE, Abuelo DN, Mitchell AA, Rasmussen SA. Reviewing the evidence for mycophenolate mofetil as a new teratogen: Case report and review of the literature. Am J Med Genet A 2009;149A:1241-8.

32. Merlob P, Stahl B, Klinger G. Tetrada of the possible mycophenolate mofetil embryopathy: A review. Reprod Toxicol 2009;28:105-8.

33. Tjeertes IF, Bastiaans DE, van Ganzewinkel CJ, Zegers SH. Neonatal anemia and hydrops fetalis after maternal mycophenolate mofetil use. J Perinatol 2007;27:62-4.

34. Coffin CS, Shaheen AA, Burak KW, Myers RP. Pregnancy outcomes among liver transplant recipients in the United States: A nationwide case-control analysis. Liver Transpl 2010;16:56-63.

35. Jain AB, Reyes J, Marcos A, et al. Pregnancy after liver transplantation with tacrolimus immunosuppression: A single center's experience update at 13 years. Transplantation 2003;76:827-32.

36. Wu A, Nashan B, Messner U, et al. Outcome of 22 successful pregnancies after liver transplantation. Clin Transplant 1998;12:454-64.

37. Ville Y, Fernandez H, Samuel D, Bismuth H, Frydman R. Pregnancy in liver transplant recipients:course and outcome in 19 cases. Am J Obstet Gynecol 1993;168:896-902.

38. Sibanda N, Briggs JD, Davison JM, Johnson RJ, Rudge CJ. Pregnancy after organ transplantation:a report from the UK Transplant pregnancy registry. Transplantation 2007;83:1301-7.

39. Christopher V, Al-Chalabi T, Richardson PD, et al. Pregnancy outcome after liver transplantation: A single-center experience of 71 pregnancies in 45 recipients. Liver Transpl 2006;12:1138-43.

40. Jabiry-Zieniewicz Z, Szpotanska-Sikorska M, Pietrzak B, et al. Pregnancy outcomes among female recipients after liver transplantation: Further experience. Transplant Proc 2011;43:3043-7.

41. Radomski JS, Ahlswede BA, Jarrell BE, et al. Outcomes of 500 pregnancies in 335 female kidney, liver, and heart transplant recipients. Transplant Proc 1995;27:1089-90.

42. Nagy S, Bush MC, Berkowitz R, Fishbein TM, Gomez-Lobo V. Pregnancy outcome in liver transplant recipients. Obstet Gynecol 2003;102:121-8.

43. Kociszewska-Najman B, Pietrzak B, Cyganek A, et al. Intrauterine hypotrophy and premature births in neonates delivered by female renal and liver transplant recipients. Transplant Proc 2011;43:3048-51.

44. Patapis P, Irani S, Mirza DF, et al. Outcome of graft function and pregnancy following liver transplantation. Transplant Proc 1997;29:1565-6.

45. Raakow R, Neuhaus R, Buscher U, et al. Parenthood following liver transplantation. Transplant Proc 2001;33:1450-2.

46. Scantlebury V, Gordon R, Tzakis A, et al. Childbearing after liver transplantation. Transplantation 1990;49:317-21.

47. Wielgos M, Szpotanska-Sikorska M, Mazanowska N, et al. Pregnancy risk in female kidney and liver recipients: A retrospective comparative study. J Matern Fetal Neonatal Med 2012;25:1090-5.

48. Rayes N, Neuhaus R, David M, Steinmuller T, Bechstein WO, Neuhaus P. Pregnancies following liver transplantation - how safe are they? A report of 19 cases under cyclosporine A and tacrolimus. Clin Transplant 1998;12:396-400.

49. Dei Malatesta MF, Rossi M, Rocca B, et al. Pregnancy after liver transplantation: Report of 8 new cases and review of the literature. Transpl Immunol 2006;15:297-302.

50. Gerlei Z, Wettstein D, Rigo J, Asztalos L, Langer RM. Childbirth after organ transplantation in Hungary. Transplant Proc 2011;43:1223-4.

51. Morton A. Liver transplantation and pregnancy. Aust N Z J Obstet Gynaecol 2003;43:236-8.

52. Costa ML, Surita FG, Passini R Jr, Cecatti JG, Boin IF. Pregnancy outcome in female liver transplant recipients. Transplant Proc 2011;43:1337-9. 


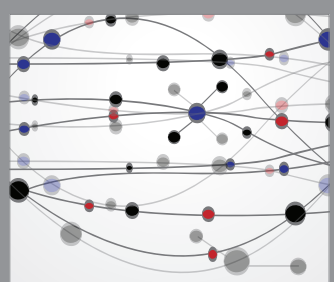

The Scientific World Journal
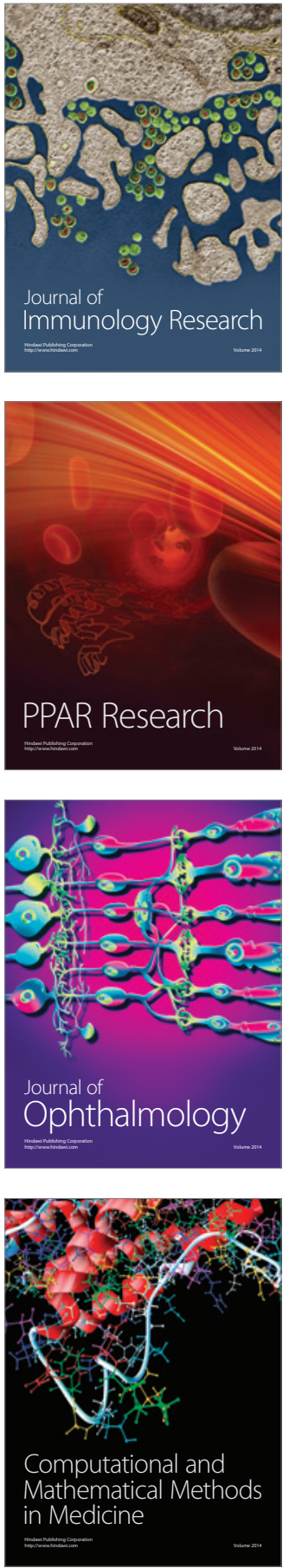

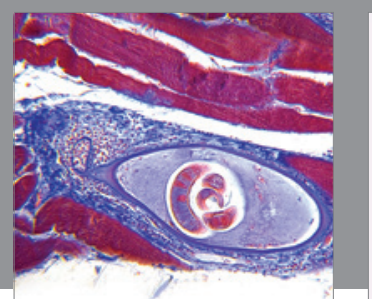

Gastroenterology Research and Practice

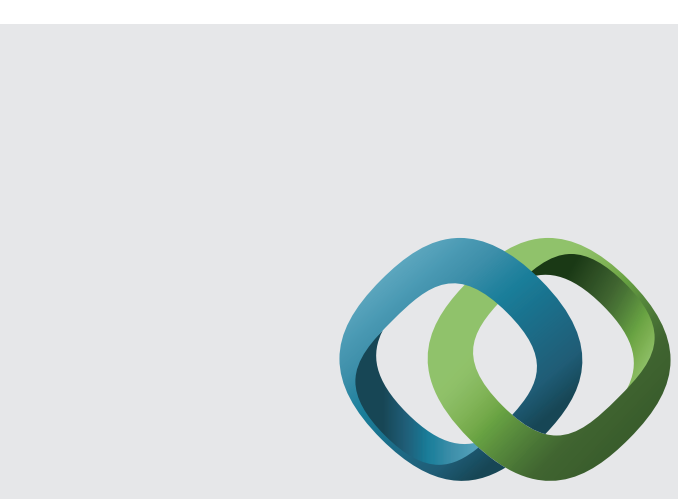

\section{Hindawi}

Submit your manuscripts at

http://www.hindawi.com
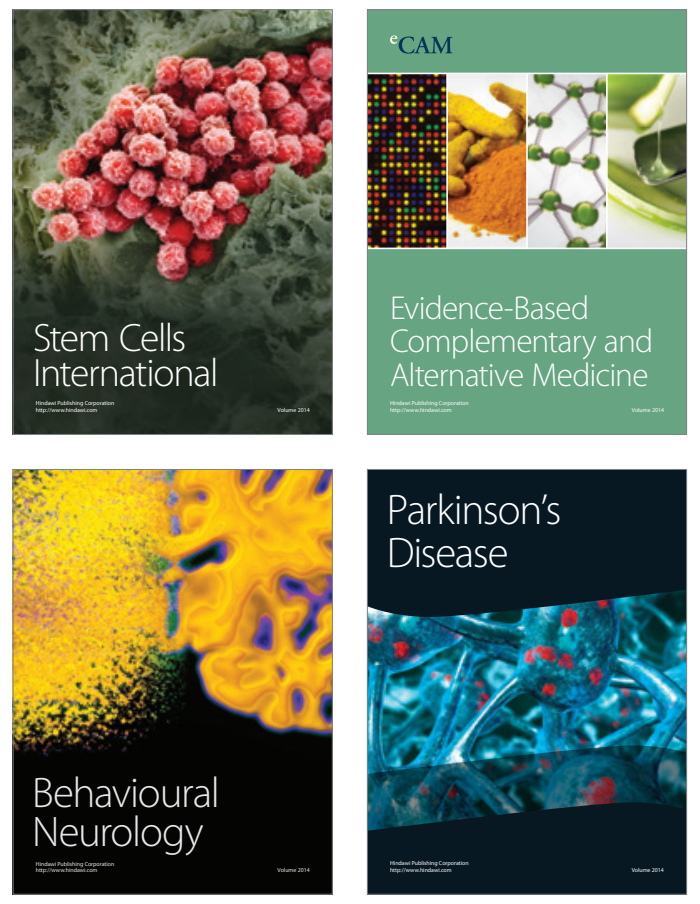
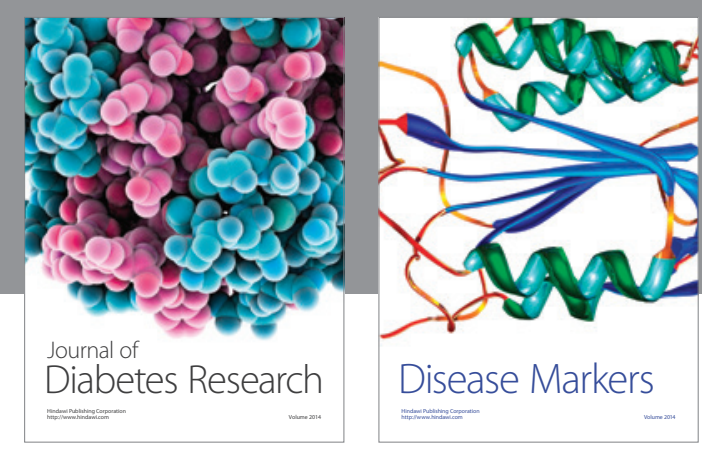

Disease Markers
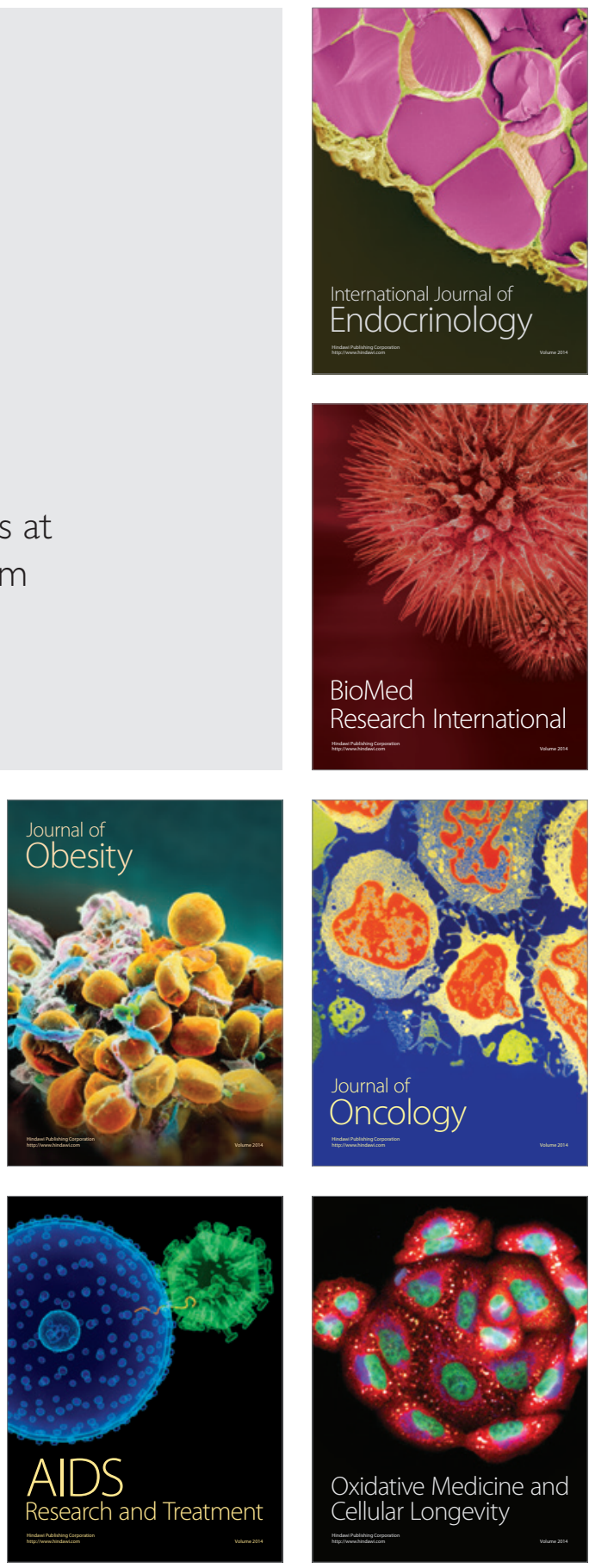